\title{
Gene expression profiles of oral leukoplakia and carcinoma: Genome-wide comparison analysis using oligonucleotide microarray technology
}

\author{
TAKESHI ODANI, DAISUKE ITO, MING-HENG LI, AI KAWAMATA, \\ TOMOHIDE ISOBE, MASAYASU IWASE and MASAO NAGUMO
}

Department of Oral \& Maxillofacial Surgery, School of Dentistry, Showa University, Tokyo 145-8515, Japan

Received September 27, 2005; Accepted November 16, 2005

\begin{abstract}
Although leukoplakia is the most common precancerous lesion of the oral cavity, its molecular biological properties are largely unknown. The aim of this study was to identify the genes responsible for its pathogenesis and malignant transformation using oligonucleotide microarray technology. The expression profiles of 8,800 genes in human oral leukoplakia $(n=4)$ and oral squamous cell carcinoma (OSCC) $(n=2)$ were analyzed using the Affymetrix GeneChip ${ }^{\circledR}$ system and the results were confirmed with RT-PCR. Eight genes were up-regulated ( $>2.0$-fold) and ten were downregulated $(<0.5$-fold $)$ in all leukoplakias analyzed with the GeneChip. In particular, loricrin and keratins displayed greater differences between normal tissue and leukoplakia. Some of the 18 alternatively expressed genes were markedly downregulated in squamous cell carcinoma compared with leukoplakia. Our data suggested that gene abnormalities in cytoskeleton network components might be responsible for the development and progression of oral leukoplakia.
\end{abstract}

\section{Introduction}

No skilled clinicians and pathologists, sophisticated diagnostic devices, nor a high degree of patient compliance is required for the detection of oral leukoplakia, a common white lesion of the oral mucosa $(1,2)$. However, strategies for the clinical management of this disease remain controversial because of the high prevalence of malignant transformation $(1,2)$. The clinical appearance and degree of epithelial dysplasia cause a less than accurate prediction of disease prognosis. It has been suggested that understanding the overall genetic events during the progression of these lesions might contribute to the elucidation of oral epithelial carcinogenesis, in addition

Correspondence to: Dr Takeshi Odani, Department of Oral \& Maxillofacial Surgery, School of Dentistry, Showa University, Kitasenzoku 2-1-1, Ohta-ku, Tokyo 145-8515, Japan

E-mail: odani@senzoku.showa-u.ac.jp

Key words: DNA chip, leukoplakia, carcinoma, loricrin, keratin to the development of more sophisticated diagnostic and treatment strategies.

Previous studies have demonstrated that oral leukoplakia and oral squamous cell carcinoma (OSCC) display unique gene expression patterns, including p53 (3-5), Ki-67 $(4,6)$, and MDM2 (5). Despite the number of studies, the elucidation of reliable prognostic markers for leukoplakia has been unsuccessful. However, it is speculated that a number of unidentified genes might be strongly correlated with disease progression and would thus be available as prediction biomarkers of cancer development.

In this study, we analyzed the gene expression profiles of human oral leukoplakia and OSCC tissues by using an Affymetrix GeneChip expression analysis system to identify genes associated with the pathogenesis and malignant transformation of oral leukoplakia. Eight thousand and eight hundred genes were analyzed using the GeneChip microarrays, revealing that several genes might be associated with pathogenesis and some could be candidates as reliable clinical biomarkers of oral leukoplakia.

\section{Patients and methods}

Patients and tissue samples. Five cases of oral leukoplakia and two cases of OSCC were examined in this study (Table I). The protocols for the use of human tissue were approved by the Ethics Committee for Genome Research, Showa University. Specimens of oral leukoplakia and OSCC were resected at the Department of Oral and Maxillofacial Surgery, Showa University Dental Hospital. Normal matched tissue was obtained from normal sites adjacent to the lesions. All cases of oral leukoplakia were classified as the 'Simplex' type according to the classification by Súgar and Bánóczy (7). In case 1, OSCC was observed to have developed within tongue leukoplakia during clinical follow-up for leukoplakia. These two lesions were excised en bloc and then handled separately during the experiments. Excised tissue was immediately snapfrozen in liquid nitrogen and stored at $-80^{\circ} \mathrm{C}$ until use. Total cellular RNA was extracted from the frozen samples by using TRIzol $^{\circledR}$ agent (Life Technologies, Gaithersburg, MD, USA) according to the manufacturer's recommendations. The RNA purity and yield were measured by spectrophotometric absorbance at 260 and $280 \mathrm{~nm}$. The quality of the isolated RNA samples was routinely confirmed by examining the integrity 
Table I. Patients participating in this study.

\begin{tabular}{lccccc}
\hline $\begin{array}{l}\text { Case } \\
\text { no. }\end{array}$ & Sex & $\begin{array}{c}\text { Age } \\
\text { (years) }\end{array}$ & $\begin{array}{c}\text { Affected } \\
\text { site }\end{array}$ & $\begin{array}{c}\text { Pathological } \\
\text { diagnosis }\end{array}$ & $\begin{array}{c}\text { Epithelial } \\
\text { dysplasia }\end{array}$ \\
\hline 1 & M & 76 & $\begin{array}{c}\text { Tongue } \\
\text { Tongue }\end{array}$ & $\begin{array}{c}\text { Leukoplakia } \\
\text { OSCC }\end{array}$ & No \\
2 & F & 57 & Tongue & Leukoplakia & Mild \\
3 & F & 66 & Cheek & Leukoplakia & Mild \\
4 & F & 73 & Tongue & Leukoplakia & No \\
5 & M & 71 & Tongue & OSCC & \\
6 & M & 68 & Gingiva & Leukoplakia & Moderate \\
7 & M & 76 & Gingiva & Leukoplakia & No \\
\hline
\end{tabular}

of $28 \mathrm{~S}$ and $18 \mathrm{~S}$ ribosomal RNA bands by electrophoresis on agarose gels.

Probe preparation for oligonucleotide array hybridization. Ten $\mu \mathrm{g}$ of total cellular RNA was converted into doublestranded cDNA by using a SuperScript ${ }^{\mathrm{TM}}$ Choice system (Invitrogen Life Technologies, Carlsbad, CA, USA). In this protocol, oligo $(\mathrm{dT})_{24}$ primer containing a T7 RNA polymerase promoter site was used. T7-(dT) $)_{24}$ primer used in this study was as follows: GGC CAG TGA ATT GTA ATA CGA CTC ACT ATA GGG AGG CGG-(dT) ${ }_{24}$. Double-stranded cDNA was purified by using a Phase Lock Gel (Eppendorf, Hamburg, Germany). The biotinylated complementary RNA (cRNA) was synthesized by an in vitro transcription (IVT) reaction using T7 RNA polymerase (BioArray High Yield RNA Transcript Labeling Kit; Enzo Life Sciences, New York, NY, USA) supplemented with biotin-CTP and biotin-UTP. The labeled cRNA was purified by using an RNeasy ${ }^{\circledR}$ mini kit (Qiagen, Hilden, Germany) and fragmented randomly to an average size of approximately $35-200$ bases by mild alkaline treatment at $94^{\circ} \mathrm{C}$ for $35 \mathrm{~min}$ in fragmentation buffer $(200 \mathrm{mM}$ Tris-acetate, $\mathrm{pH} 8.1,500 \mathrm{mM}$ potassium acetate, $150 \mathrm{mM}$ magnesium acetate). The hybridization cocktail was composed of $0.05 \mu \mathrm{g} / \mu 1$ of fragmented cRNA, $100 \mathrm{mM}$ MES (2-[NMorpholino] ethanesulfonic acid), $1 \mathrm{M}\left[\mathrm{Na}^{+}\right], 20 \mathrm{mM}$ EDTA, $0.01 \%$ Tween-20, $0.1 \mathrm{mg} / \mathrm{ml}$ of herring sperm DNA and $0.5 \mathrm{mg} / \mathrm{ml}$ of acetylated BSA. In addition, the hybridization cocktail contained a mixture of four control cRNAs for bacterial and phage genes $(1.5,5,25$, and $100 \mathrm{pM}$ of $\mathrm{BioB}, \mathrm{BioC}$, BioD and Cre, respectively) to serve as comparison tools for hybridization efficiency between arrays. A biotinylated oligonucleotide B2 that specifically hybridized to features at the center and corners of the chip was also added to the cocktail to allow correct orientation and recognition of the probe sets.

Hybridization and scanning. The hybridization cocktail was heated at $99^{\circ} \mathrm{C}$ for $5 \mathrm{~min}$, followed by incubation at $45^{\circ} \mathrm{C}$ for $5 \mathrm{~min}$ and centrifugation $(15.000 \mathrm{rpm})$ for $5 \mathrm{~min}$ at room temperature. An aliquot of the hybridization cocktail $(10 \mu \mathrm{g}$ fragmented cRNA in $200 \mu 1$ of hybridization cocktail) was hybridized on a GeneChip human genome focus array for $16 \mathrm{~h}$ at $45^{\circ} \mathrm{C}$. The array was washed and stained according to the Affymetrix protocol with biotinylated goat anti-streptavidin antibody (Vector Laboratories, Burlingame, CA, USA) and streptavidin-phycoerythrin (Molecular Probes Inc., Eugene, OL, USA) on Affymetrix Fluidics Station $400^{\circledR}$. The array was then scanned using a GeneArray ${ }^{\circledR}$ Scanner argon-ion laser confocal microscope (Agilent, CA, USA).

Data analysis. The digitized image data was processed using Microarray Suite ${ }^{\circledR}$ ver. 5.0 and Data Mining Tool ${ }^{\circledR}$ ver. 3.0 software (Affymetrix).

Detection algorithm. The detection algorithm used probe pair intensities to generate a detection $\mathrm{p}$-value and was assigned as Present, Marginal, or Absent. The detection p-value was determined by calculating the discrimination score [R] for each probe pair. The discrimination score was measured by the target-specific intensity difference of the probe pair [perfect match (PM) and mismatch (MM)] relative to its overall hybridization intensity $(\mathrm{PM}+\mathrm{MM}): \mathrm{R}=(\mathrm{PM}-\mathrm{MM}) /$ $(\mathrm{PM}+\mathrm{MM})$.

Signal algorithm. The signal was a quantitative metric calculated for each probe set, which represents the relative level of expression of a transcript. The signal was calculated using One-Step Tukey's Biweight Estimate, which yielded a robust weighted mean that was relatively insensitive to outliers, even when extreme.

Comparison analysis (experiment versus baseline arrays). In comparison analyses, two samples hybridized to two GeneChip arrays of the same type were compared with each other to detect and quantify the changes in gene expression. The analyses compared the difference values (PM-MM) of each probe pair in the baseline array to its matching probe pair on the experiment array. Two sets of algorithms were used to generate change significance and change quantity metrics for each probe set. A change algorithm generated a change p-value and an associated change. A second algorithm produced a quantitative estimate of the change in gene expression in the form of a signal log ratio. Before comparing two arrays, scaling or normalization was applied. Scaling and normalization was corrected for variations between the two arrays. Wilcoxon's signed rank test was used in the comparison analysis to derive biologically meaningful results from the raw probe cell intensities on expression arrays. During comparison analyses, each probe set on the experiment array was compared to its counterpart on the baseline array, and a change p-value was calculated, indicating an increase, decrease, or no change in gene expression.

Change p-value. Wilcoxon's signed rank test used the differences between PM and MM intensities, as well as the differences between PM intensities and background to compute each change p-value. From Wilcoxon's signed rank test, three one-sided p-values were computed for each probe set. Hence, the $\mathrm{p}$-value scale was used to generate discrete change calls using thresholds. These thresholds will be described in the Change call section.

Reverse transcription (RT)-PCR. One $\mu \mathrm{g}$ of total RNA was subjected to first-strand cDNA synthesis and subsequent PCR 


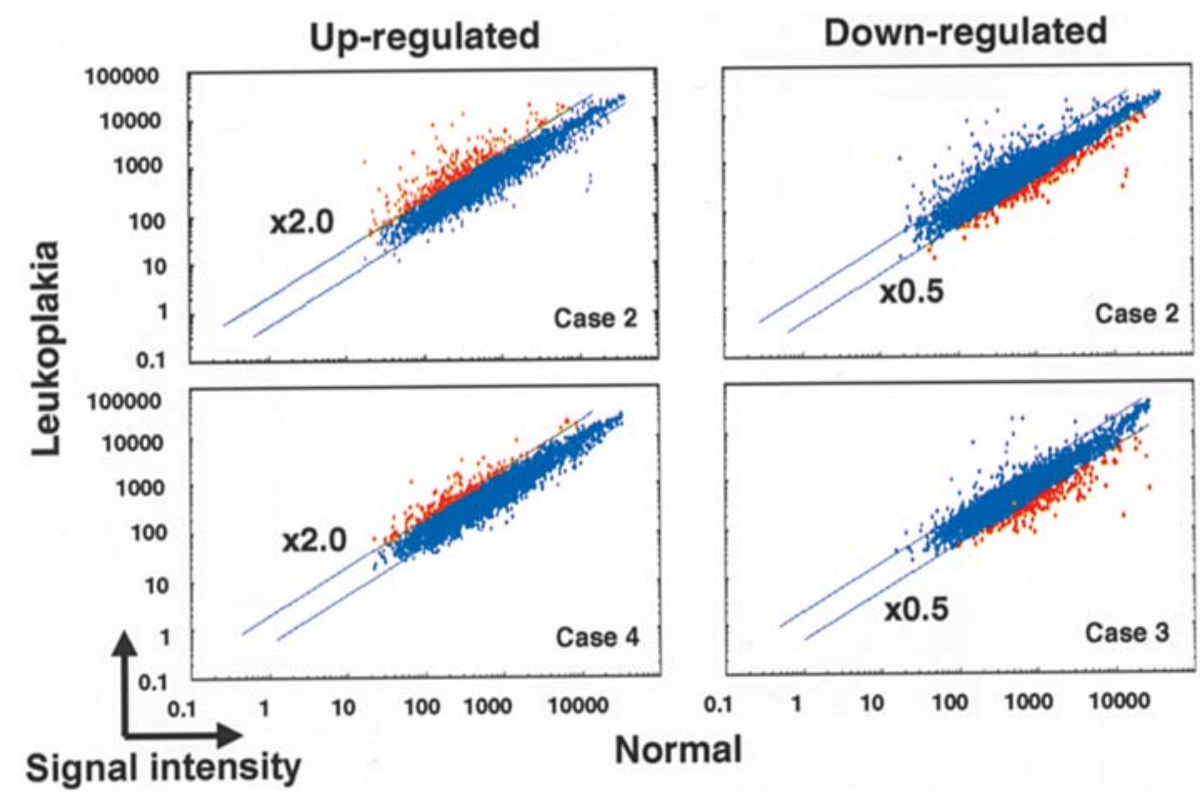

Figure 1. Scatter plots of the signal intensity values for the 8,800 genes in normal mucosa (X-axis) compared with leukoplakia (Y-axis) represented on the GeneChip. Samples from oral leukoplakia and matched normal tissue were analyzed using the Affymetrix GeneChip as described in Materials and methods. Genes up-regulated and down-regulated in leukoplakia are represented as orange and red dots, respectively. The upper and lower boundaries represent 2.0fold and 0.5-fold differences, respectively. Representative data from cases 1-4 are shown.

Table II. Genes up-regulated in the oral leukoplakia of cases $1-4$.

\begin{tabular}{|c|c|}
\hline Probe set & Description \\
\hline 220414_at & $\begin{array}{l}\text { Homo sapiens calmodulin-like skin protein } \\
\text { (CLSP) }\end{array}$ \\
\hline 213287_s_at & $\begin{array}{l}\text { Human gene for acidic (type I) cytokeratin } 10 \\
\text { (K10) }\end{array}$ \\
\hline 207908_at & $\begin{array}{l}\text { Homo sapiens keratin 2e (epidermal } \\
\text { ichthyosis bullosa of Siemens) (K2e) }\end{array}$ \\
\hline 207720_at & Homo sapiens loricrin (LOR) \\
\hline 206662_at & $\begin{array}{l}\text { Homo sapiens glutaredoxin (thioltransferase) } \\
\text { (GLRX) }\end{array}$ \\
\hline 206643_at & Homo sapiens histidine ammonia-lyase (HAL) \\
\hline 206177_s_at & Homo sapiens arginase-1, liver (ARG1) \\
\hline 204469_at & $\begin{array}{l}\text { Homo sapiens protein tyrosine phosphatase, } \\
\text { receptor-type, Z polypeptide } 1 \text { (PTPRZ1) }\end{array}$ \\
\hline
\end{tabular}

with an RNA PCR kit (AMV) ver. 2.1 using a programmed temperature control system (Astec, Fukuoka, Japan). PCR primers used in this study were as follows: ACG TCT CCT CGC AGC AGG (sense) and CTA TTT GGA CGG CCA GGT (antisense) for loricrin; TGA AGG TCG GAG TCA ACG GAT TTG (sense) and CAT GTG GGC CAT GAG GTC CAC CAC (antisense) for GAPDH.

\section{Results}

The differential expression of the 8,800 known genes in four cases of leukoplakia (cases 1-4 in Table I) and two cases of
Table III. Genes down-regulated in the oral leukoplakia of cases 1-4.

Probe set Description

201884_at Homo sapiens carcinoembryonic antigenrelated cell adhesion molecule 5 (CEACAM5)

202790_at Homo sapiens claudin 7 (CLDN7)

203108_at Homo sapiens retinoic acid induced 3 (RAI3)

203757_s_at Homo sapiens, carcinoembryonic antigenrelated cell adhesion molecule 6 (non-specific cross reacting antigen) (CEACAM6)

205319_at Homo sapiens prostate stem cell antigen (PSCA)

206884_s_at Homo sapiens sciellin (SCEL)

209365_s_at Human extracellular matrix protein 1 (ECM1)

210827_s_at Homo sapiens epithelial-specific transcription factor ESE-la (ESE-1)

212657_s_at Homo sapiens IL-1 receptor antagonist IL-1 $\mathrm{Ra}$ (IL-1 RA) gene, alternatively spliced forms, complete cds

219554_at Homo sapiens Rh type C glycoprotein (RHCG)

OSCC (cases 1 and 5) was analyzed using GeneChip. The distribution of signal intensity is shown in the scatter graphs of Fig. 1. Most of the genes were distributed along the diagonal lines of the graphs, indicating that the experimental procedures were successful. The boundaries in the graphs indicate the cut-off lines (2.0-fold and 0.5 -fold difference 


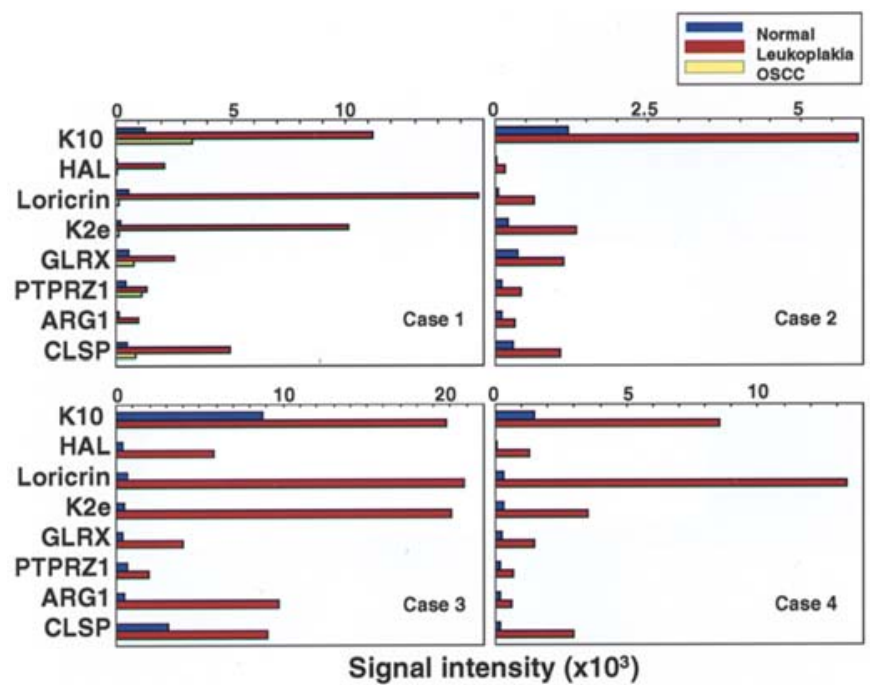

Figure 2. Expression of the eight up-regulated genes in leukoplakia, OSCC, and normal mucosa from cases 1-4. Abbreviations appear in Table II.

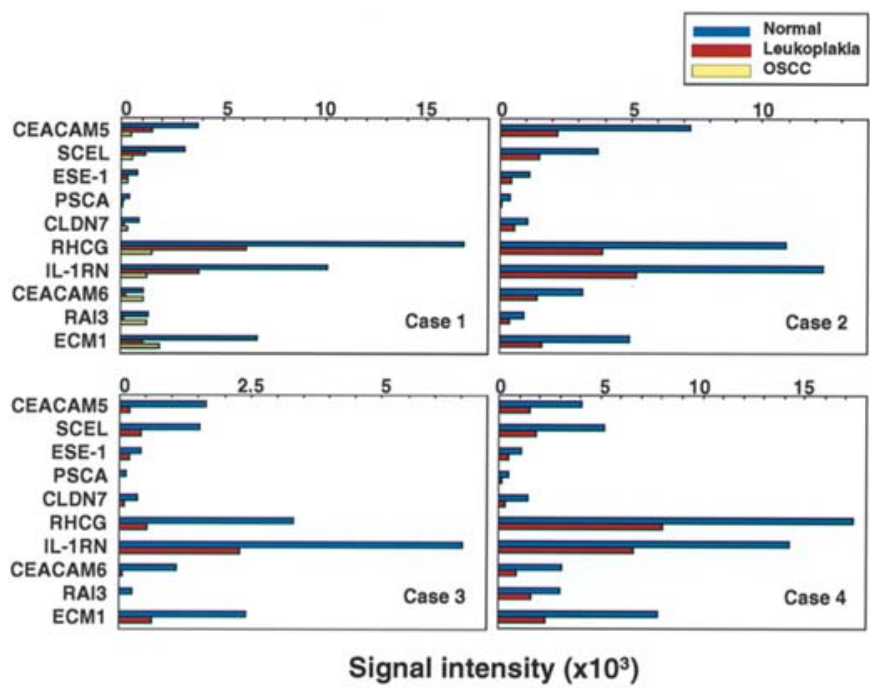

Figure 3. Expression of the ten down-regulated genes in leukoplakia, OSCC, and normal mucosa from cases 1-4. Abbreviations appear in Table III.
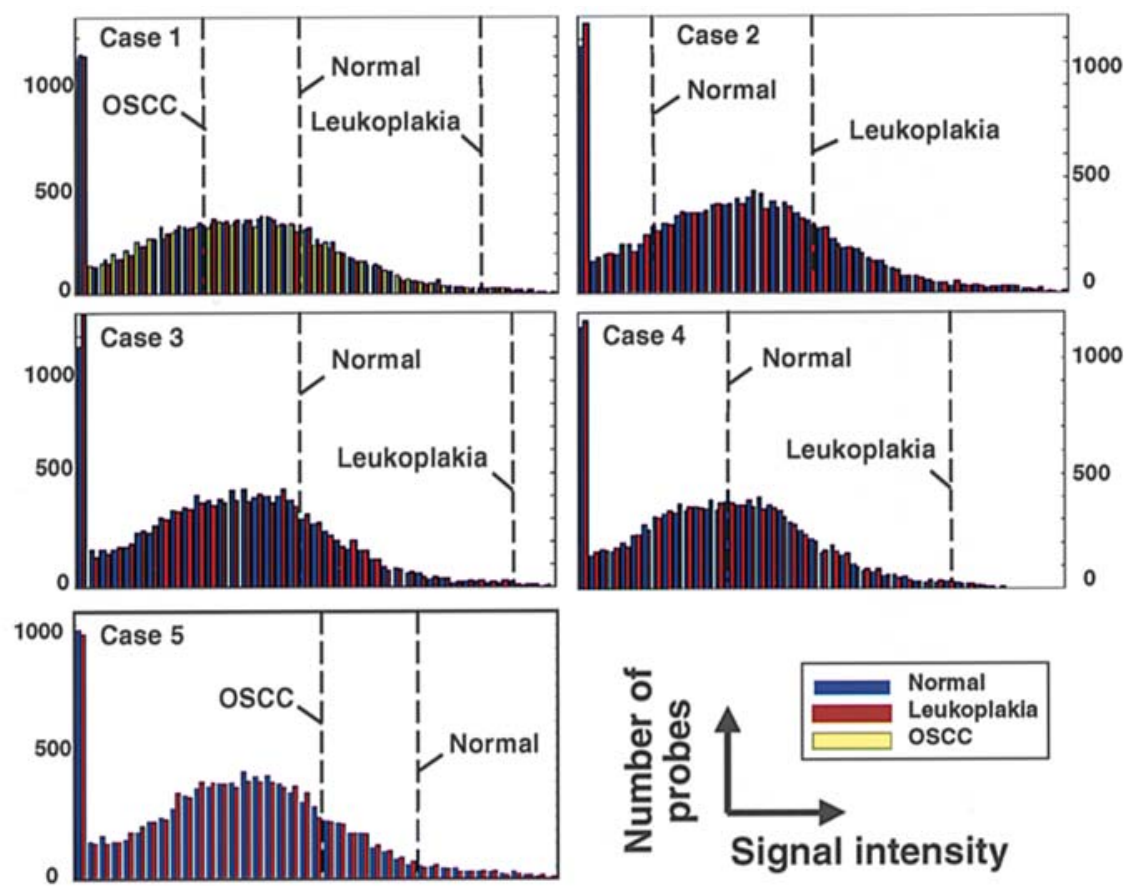

Figure 4. Distribution of signal intensity of the 8,800 genes and the ranking of the loricrin gene. The signal intensities of the loricrin gene in leukoplakia, OSCC, and normal mucosa are indicated with dashed lines.

in signal intensity in leukoplakia compared with normal mucosa). The orange and red dots indicate genes up-regulated and down-regulated in leukoplakia, respectively. Each case had approximately 200 alternatively expressed genes.

This was too many genes for our purpose, so we focused on those that were commonly alternatively expressed in all cases of leukoplakia analyzed with GeneChip. Eighteen genes were selected using this criterion. Eight genes $(0.091 \%$ of the 8,800 genes) displayed more than 2.0-fold signal intensity (up-regulated genes) and ten genes $(0.114 \%)$ displayed lower than 0.5 -fold signal intensity (down-regulated genes) in all cases of leukoplakia. The up-regulated and down-regulated genes are listed in Tables II and III, respectively.
The list of up-regulated genes is comprised of genes for the components of the keratinocyte cytoskeleton network: loricrin, K2e, and K10 (Table II). Only four genes (loricrin, $\mathrm{K} 2 \mathrm{e}, \mathrm{K} 10$, and CLSP) were epithelia-specific. On the other hand, only one gene (SCEL) in the list of down-regulated genes was associated with the cornified cell envelope of the epithelial cells. Some genes were correlated with epithelial cell adhesion (CLDN7), cancer antigen (CEACAM5 and CEACAM6), keratinocyte activation (IL1RN and RAI-3), transcription of epithelial cells (ESE-1), and epithelial cell embryonicity (PSCA-1).

The signal intensities of the up-regulated genes in cases 1-4 are displayed in Fig. 2. All genes, except for K10, were 


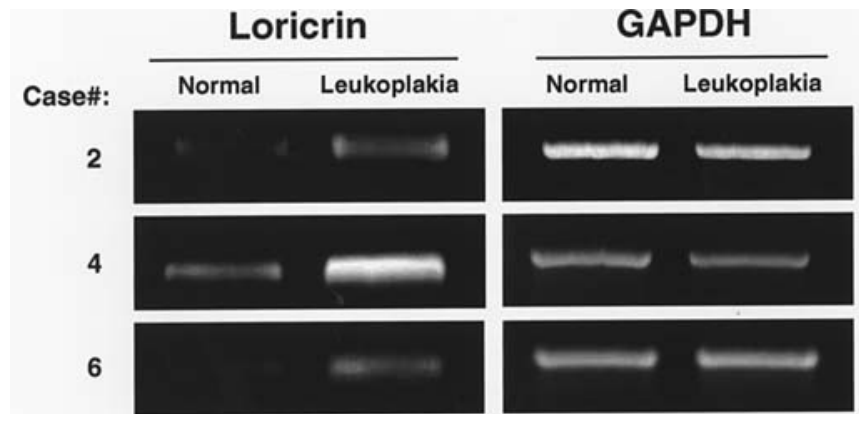

Figure 5. RT-PCR analysis of loricrin expression in normal mucosa and leukoplakia. Samples from cases 2, 4, and 6 were subjected to RT-PCR as described in Materials and methods.

only weakly expressed or were almost absent in the normal mucosa. K10 was augmented in leukoplakia in all cases. The loricrin gene displayed significant differences in signal intensity between normal tissue and leukoplakia (3.36-39.9-fold). K2e was also strongly expressed in leukoplakia in cases 1, 3, and 4. The expression of loricrin and $\mathrm{K} 2 \mathrm{e}$ was weaker in case 2, in which the signals of other genes were also lower. All the up-regulated genes, except for PTPRZ1, were down-regulated in OSCC developed from the tongue leukoplakia of case 1.

Similarly, the signal intensities of the down-regulated genes in cases 1-4 are displayed in Fig. 3. Rh type $\mathrm{C}$ glycoprotein (RHCG) and IL-1 receptor antagonist (IL-1RN) were strongly expressed in normal tissue and decreased in leukoplakia. However, differences in the signal intensity between normal tissue and leukoplakia were smaller than in the up-regulated genes, whereas leukoplakia/OSCC differences were greater than normal/leukoplakia differences. The expression of RHCG and IL-1RN was remarkably suppressed in the OSCC of case 1. Similar expression patterns were obtained in CEACAM5 and SCEL.

Of the genes alternatively expressed in the lesions, we focused on the loricrin gene because of its higher signal intensity and greater dynamic range of change in expression. The distribution of its signal intensity in cases 1-5 is shown in Fig. 4. Loricrin expression in leukoplakia was ranked in the top-end group in cases 1, 3, and 4. Even in case 2, in which loricrin expression was relatively low, the ranking of loricrin appeared far beyond the average. In the OSCC of cases 1 and 5, loricrin expression was lower than in normal tissue. These data suggested that differences in loricrin expression could be easily detected by simple transcription assays such as RT-PCR. If conventional RT-PCR is available, the loricrin gene may be easily used in a routine clinical examination for the prediction or early detection of malignant transformation.

To address this issue, RT-PCR for loricrin gene expression was performed. Remarkable differences in loricrin expression between normal tissue and leukoplakia were also detected by RT-PCR (Fig. 5). Case 6 was not analyzed using GeneChip because of an insufficient amount of tissue specimen. In this case, loricrin was almost below the detectable level in normal tissue but was clearly detected in leukoplakia. In case 4 , the intensity of the loricrin band in leukoplakia was beyond that of the housekeeping gene, GAPDH. These results demonstrated that data similar to those from GeneChip were obtained by conventional RT-PCR.

\section{Discussion}

Detailed studies on differential gene expression are required to further understand the molecular pathogenesis of oral leukoplakia and OSCC. However, literature on the genomewide analysis of oral cancers and precancerous lesions has been extremely limited. In this study, we attempted to identify the genes associated with the pathogenesis of oral leukoplakia and the mechanism of epithelial carcinogenesis using the Affymetrix GeneChip cDNA microarray system.

Conventional methods of transcription analysis, such as Northern blotting and RT-PCR, have imposed a practical limit on the number of genes analyzed. The current technological progress of highly-integrated cDNA microarrays, so-called 'DNA chips', enables us to monitor the expression level of thousands of genes rapidly and simultaneously $(8,9)$. The small cm_ chip is a good tool for the complex genome-wide screening of known genes. We can monitor the changes in gene expression patterns with a small tissue sample or cultured cells under the given conditions. A larger volume of data is obtained and a database of gene expression profiles can be easily constructed with the 'DNA chips' system.

Of the eight up-regulated genes, loricrin, K2e, and K10 displayed greater differences in signal intensity between normal and leukoplakia tissues. Interestingly, these three genes were expressed only weakly or were almost under the detectable level in carcinoma tissues from cases 1 and 5 (Fig. 5).

Keratins have been intensively analyzed for their association with the carcinogenesis and malignant phenotypes of several types of carcinomas. Bloor et al (10) examined K2e/K10 expression in oral mucosal dysplasia and OSCC, and obtained data similar to our observations. Loricrin, one of the major components of the cornified cell envelope, is induced and strongly expressed at the later stage of epithelial differentiation (11-13). Several factors, such as loricrin, involucrin, sciellin, and small proline-rich proteins, have been implicated in this differentiation as precursor proteins of the cornified cell envelope (13-16). There is limited information on the correlation between these cytoskeleton network genes and oral premalignant lesions (17). Re-arrangement of the cytoskeleton occurs during cell division and, thus, abnormalities in the cornified envelope components may be associated with, or even responsible for, molecular events during the formation of dysplasia and malignant transformation $(18,19)$. Further studies are needed to clarify these issues.

All ten down-regulated genes are associated with the function, differentiation, and transformation of epithelial cells. Of them, rhesus antigen type $\mathrm{C}$ glycoprotein (RhCG), a splice variant of the IL-1 receptor antagonist (IL-1RA), and SCEL displayed higher signal intensities in normal tissue, marked down-regulation in leukoplakia, and further reduction in OSCC.

Human RhCG is a non-erythroid homologue of the rhesus blood-antigen group and is expressed in certain tissues, including squamous epithelia $(20,21)$. It has been reported that its expression is lost or dramatically reduced in primary esophageal cancer tissue (21). Our data from leukoplakia and OSCC corresponded well with these previous reports. IL-1 is an important cytokine in keratinocyte biology and IL-1RA works as a regulator of the IL-1 function. There are a number 
of publications describing the contribution of the IL-1 network in cancer biology $(22,23)$. Our findings suggested that the IL-1 network plays a certain role in the pathogenesis of leukoplakia as well as OSCC. SCEL is a component of the cornified cell envelope (16) and SCEL protein is produced by the cells of squamous epithelia and keratin organs (24). Although the contribution of these factors to the development of leukoplakia and OSCC is unknown, studies of these factors will provide suggestions and explanations for the molecular pathogenesis of these diseases.

We expect from our data that alternatively expressed genes are potentially useful biomarkers for the prediction of malignant transformation. In GeneChip analyses, some of the listed genes displayed greater dynamic signal ranges between normal tissue and leukoplakia, and between leukoplakia and OSCC. We confirmed that loricrin gene expression was easily detected using RT-PCR (Fig. 5), suggesting that loricrin might be available for clinical examinations in addition to conventional cancer antigens. Not only simple expression analyses but also a clustering of differential expression will satisfy the requirements of clinicians.

Overall, we selected genes that might be responsible for, or at least associated with, the pathogenesis of leukoplakia and oral mucosal carcinogenesis. However, we have no information indicating that the differential expression patterns of these genes are disease-specific. Oral dyskeratotic lesions other than leukoplakia should be examined to address this problem. Gene expression analyses of dysplastic keratinocytes captured with a micro-dissection technique are underway to monitor the events responsible for the formation of epithelial dysplasia.

\section{Acknowledgements}

This work was supported in part by a Showa University Grant-in-Aid for Innovative Collaborative Research Projects and a Special Research Grant-in-Aid for Development and Characteristic Education from the Ministry of Education, Culture, Sports, Science, and Technology of Japan.

\section{References}

1. Bouquot JE: Oral leukoplakia and erythroplakia: A review and update. Pract Periodontics Aesthet Dent 6: 9-17, 1994.

2. Lind PO: Malignant transformation in oral leukoplakia. Scand $\mathbf{J}$ Dent Res 95: 449-455, 1987.

3. Murti PR, Warnakulasuriya KA, Johnson NW, Bhonsle RB, Gupta PC, Daftary DK and Mehta FS: p53 expression in oral precancer as a marker for malignant potential. J Oral Pathol Med 27: 191-196, 1998.

4. Kurosawa H, Matsumoto S, Murata T, Yamashita Y, Tomoyose T, Zhang M, Fukuyama $\mathrm{H}$ and Takahashi T: Immunohistochemical study of syndecan-1 down-regulation and the expression of p53 protein or Ki-67 antigen in oral leukoplakia with or without epithelial dysplasia. J Oral Pathol Med 32: 513-521, 2003.

5. Agarwal S, Mathur M, Srivastava A and Ralhan R: MDM2/p53 co-expression in oral premalignant and malignant lesions: potential prognostic implications. Oral Oncol 35: 209-216, 1999.
6. Kovesi G and Szende B: Changes in apoptosis and mitotic index, p53 and Ki67 expression in various types of oral leukoplakia. Oncology 65: 331-336, 2003.

7. Súgar L and Bánóczy J: Follow-up studies in oral leukoplakia. Bull World Health Organ 41: 289-293, 1969.

8. Lipshutz RJ, Fodor SP, Gingeras TR and Lockhart DJ: High density synthetic oligonucleotide arrays. Nat Genet 21: 20-24, 1999.

9. Welsh JB, Zarrinkar PP, Sapinoso LM, Kern SG, Behling CA, Monk BJ, Lockhart DJ, Burger RA and Hampton GM: Analysis of gene expression profiles in normal and neoplastic ovarian tissue samples identifies candidate molecular markers of epithelial ovarian cancer. Proc Natl Acad Sci USA 98: 1176-1181, 2001.

10. Bloor BK, Tidman N, Leigh IM, Odell E, Dogan B, Wollina U, Ghali $\mathrm{L}$ and Waseem A: Expression of keratin $\mathrm{K} 2 \mathrm{e}$ in cutaneous and oral lesions: association with keratinocyte activation, proliferation, and keratinization. Am J Pathol 162: 963-975, 2003.

11. Mehrel T, Hohl D, Rothnagel JA, Longley MA, Bundman D, Cheng C, Lichti U, Bisher ME, Steven AC, Steinert PM, et al: Identification of a major keratinocyte cell envelope protein, loricrin. Cell 61: 1103-1112, 1990.

12. Hohl D, Mehrel T, Lichti U, Turner ML, Roop DR and Steinert PM: Characterization of human loricrin. Structure and function of a new class of epidermal cell envelope proteins. J Bio Chem 266: 6626-6636, 1991.

13. Hohl D, Ruf Olano B, De Viragh PA, Huber M, Detrisac CJ, Schnyder UW and Roop DR: Expression patterns of loricrin in various species and tissues. Differentiation 54: 25-34, 1993.

14. Hohl D: Cornified cell envelope. Dermatologica 180: 201-211, 1990.

15. Backendorf C and Hohl D: A common origin for cornified envelope proteins? Nat Genet 2: 91, 1992.

16. Kvedar JC, Manabe M, Phillips SB, Ross BS and Baden HP: Characterization of sciellin, a precursor to the cornified envelope of human keratinocytes. Differentiation 49: 195-204, 1992.

17. Kannan S, Balaram P, Chandran GJ, Pillai MR, Mathew B, Nalinakumari KR and Nair MK: Differential expression of cytokeratin proteins during tumour progression in oral mucosa. Epithelial Cell Biol 3: 61-69, 1994.

18. Itoiz ME, Conti CJ, Gimenez IB, Lanfranchi HE, FernandezAlonso GI and Klein-Szanto AJ: Immunodetection of involucrin in lesions of the oral mucosa. J Oral Pathol 15: 205-208, 1986.

19. Itoiz ME, Conti CJ, Lanfranchi HE, Mamrack M and KleinSzanto AJ: Immunohistochemical detection of filaggrin in preneoplastic and neoplastic lesions of the human oral mucosa. Am J Pathol 119: 456-461, 1985.

20. Liu Z, Chen Y, Mo R, Hui C, Cheng JF, Mohandas N and Huang CH: Characterization of human RhCG and mouse RhCG as novel nonerythroid $\mathrm{Rh}$ glycoprotein homologues predominantly expressed in kidney and testis. J Biol Chem 275: 25641-25651, 2000.

21. Chen BS, Xu ZX, Xu X, Cai Y, Han YL, Wang J, Xia SH, Hu H, Wei F, Wu M and Wang MR: RhCG is downregulated in oesophageal squamous cell carcinomas, but expressed in multiple squamous epithelia. Eur J Cancer 38: 1927-1936, 2002.

22. Thomas GR, Chen Z, Leukinova E, Van Waes C and Wen J: Cytokines IL-1 alpha, IL-6, and GM-CSF constitutively secreted by oral squamous carcinoma induce down-regulation of CD80 costimulatory molecule expression: restoration by interferon gamma. Cancer Immunol Immunother 53: 33-40, 2004.

23. Moriya T, Seki N, Shimada K, Kato M, Yakushiji T, Nimura Y, Uzawa K, Takiguchi $M$ and Tanzawa H: In-house cDNA microarray analysis of gene expression profiles involved in SCC cell lines. Int J Mol Med 12: 429-435, 2003.

24. Champliaud MF, Burgeson RE, Jin W, Baden HP and Olson PF: cDNA cloning and characterization of sciellin, a LIM domain protein of the keratinocyte cornified envelope. J Biol Chem 273: 31547-31554, 1998 . 